\title{
Modelo para aplicação de critérios ambientais para licenciamento de empreendimentos hidrelétricos, estudo de caso na sub-bacia hidrográfica do Rio Benedito-SC
}

\section{Odair Fernandes Noemia Bohn}

RESUMO: O Brasil possui condições favoráveis para a geração de energia hidráulica e ante o crescimento significativo deste setor nas últimas décadas, em grande parte estimulado pelo Poder Público Federal, verifica-se uma pressão sobre o sistema de licenciamento ambiental com vistas a liberar em curto espaço de tempo as licenças para localização, instalação e operação destes empreendimentos. A pressão mencionada e a ausência de critérios ambientais mais específicos para o setor hidrelétrico que possam nortear a análise dos estudos ambientais por parte do órgão licenciador, acabam por refletir na qualidade das condicionantes apostas nas licenças emitidas e consequentemente em prejuízo ao meio ambiente, natural e construído da bacia hidrográfica. Neste contexto, este artigo tem como objetivo, apresentar um modelo de aplicação de critérios ambientais para licenciamento de empreendimentos hidrelétricos, a partir de estudo de caso efetuado na Bacia Hidrográfica do rio Itajaí, especificamente na Sub-Bacia Hidrográfica do rio Benedito. Tal modelo tem como resultado um mapa de criticidade ambiental, baseado na análise das fragilidades ambientais estudadas. O mapa de criticidade ambiental pode ser utilizado pelo órgão ambiental como instrumento de apoio à tomada de decisáo nos procedimentos administrativos de licenciamento ambiental de empreendimentos hidrelétricos.

PALAVRAS-CHAVE : critérios ambientais; licenciamento ambiental; empreendimentos hidrelétricos.
ABSTRACT: Brazil has favorable conditions for the generation of hydropower and in view of the significant growth of this sector in recent decades, largely stimulated by the Federal Government, there is pressure on the environmental licensing system with a view to release in a short time licenses for location, installation and operation of these enterprises. The pressure mentioned and the absence of more specific environmental criteria for the hydroelectric power that can guide the analysis of environmental studies by the licensing organs, ultimately reflect the quality of presented restrictions in the permits issued and consequently detrimental to the environment, natural and built River Basin. In this context, this article aims t presenting a model of implementation of environmental criteria for licensing the hydroelectric projects, from the case study carried out in the Itajaí Basin, specifically in the Sub-basin of the Benedito River. This model has as its result an environmental fragility map. This map can be used as support for decision making by the environmental agency in administrative procedures for environmental licensing of hydroelectric projects.

KEYWORDS: environmental criteria; environmental licensing; hydropower projects.

\section{INTRODUÇÃO}

O Brasil é um país rico em recursos hídricos e construiu a base do seu suprimento de eletricidade com o aproveitamento da energia hidráulica. O potencial hidráulico abundante aliado à disponibilidade tecnológica nacional tem se traduzido em energia elétrica barata e competitiva. Segundo as projeçóes do Comitê Coordenador do Planejamento da Expansão dos Sistema Elétricos - CCPE, o mercado brasileiro de energia elétrica crescerá a taxas da ordem de 5,7\% ao ano, considerando a possibilidade de um cenário de crescimento da renda nacional próximo ao patamar de 4,5\%, no período de 2003 à 2012. Esta demanda por geração de energia, resulta numa maior pressão sobre o sistema de licenciamento ambiental para a instalação de empreendimentos hidrelétricos, e especificamente no caso de Santa Catarina, sem que o órgão ambiental estadual disponha de adequados instrumentos de apoio à tomada de decisão. 
A partir do levantamento de diversos estudos já existentes sobre a elaboração de critérios ambientais para o licenciamento ambiental de empreendimentos hidrelétricos (Becker e Guadagnin, 2001; Fepam, 2003; Soma, 2002; Prosul/RTK, 2002-2003), foi possível verificar a importância do uso de metodologias que saiam de uma análise focada de projeto como faz a Avaliação de Impacto Ambiental (AIA). Os critérios ambientais a ser exigidos dos novos empreendimentos hidrelétricos, devem ser compatíveis com o desenvolvimento sustentável e com uma visão estratégica do território nos moldes previstos para a Avaliação Ambiental Estratégica (AAE), a Avaliação Ambiental Integrada (AAI) e os Estudos Integrados de Bacias Hidrográficas (EIBH) (Armour, 1991; Darrieutort, 1991; Thérivel et al, 1992; Lee e Walsh, 1992; Sheat,1992; Wilson,1993; Partidário, 1999; Agmarn, 2004; e Tucci, 2006).

Verificou-se que a AAE, AAI e EIBH podem contribuir no sentido de subsidiar os diversos agentes envolvidos no planejamento do setor elétrico, na identificação dos impactos cumulativos e sinérgicos da implementação de um conjunto de aproveitamentos em uma determinada bacia e com isso identificar quais seriam os aproveitamentos mais viáveis de se prosseguir no processo de planejamento. Além do que, tais avaliaçóes podem proporcionar o suporte necessário aos órgãos gestores de recursos hídricos e de meio ambiente no processo de outorga de recursos hídricos e licenciamento ambiental, respectivamente.
De modo geral, qualquer que seja a nomenclatura utilizada, o que ficou evidente na pesquisa, voltada para a gestáo de recursos hídricos e sua relação com a instalação de empreendimentos hidrelétricos, é a necessidade de um estudo que procure avaliar de maneira integrada a bacia hidrográfica no sentido de harmonizar o planejamento do setor elétrico com o equacionamento das questóes ambientais.

Da análise de estudos similares de identificação de critérios ambientais para licenciamento de empreendimentos hidrelétricos realizados no Estado do Rio Grande do Sul, na bacia hidrográfica do rio Taquari Antas (Becker e Guadagnin, 2001) e na Bacia 75 (Fepam/RS, 2003); no Estado do Paraná, na bacia hidrográfica do rio Chopim (Soma, 2002); e, no Estado de Santa Catarina, na bacia hidrográfica do rio Caveiras (Prosul/RTK, 2002-2003), foi possível identificar uma série de critérios que podem servir de base teórica para a proposição de um modelo a ser utilizado como instrumento de apoio à tomada de decisão dos órgãos ambientais.

Este artigo portanto, tem por objetivo apresentar um modelo de aplicação de critérios ambientais para licenciamento de empreendimentos hidrelétricos, denominado Mapa de Criticidade Ambiental, a partir de estudo de caso efetuado na Bacia Hidrográfica do rio Itajaí, especificamente na Sub-Bacia Hidrográfica do rio Benedito, que possa auxiliar a Fundação de Meio Ambiente de Santa Catarina (FATMA) a se posicionar de forma mais criteriosa nos procedimentos de licenciamento ambiental de tais empreendimentos.
FIGURA 1. Localização da SBH do rio Benedito. Fonte: (Fernandes, 2008).

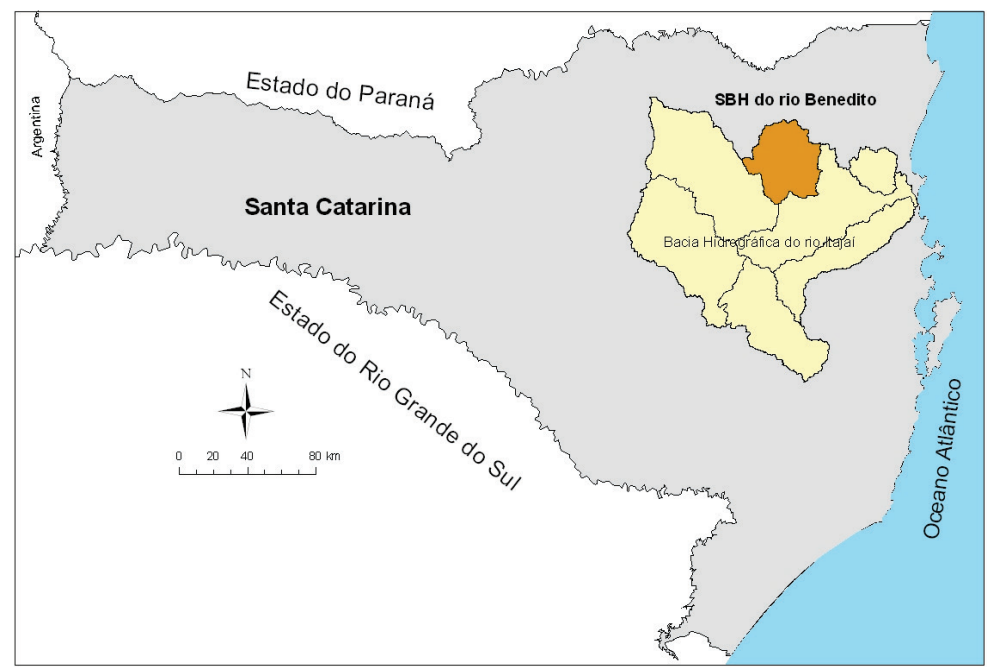




\section{METODOLOGIA}

A Sub-Bacia Hidrográfica do rio Benedito $(\mathrm{SBH}$ do rio Benedito), está localizada na região Norte da Bacia Hidrográfica do rio Itajaí, no Estado de Santa Catarina e é compreendida pelos municípios de Timbó, Rodeio, Benedito Novo, Doutor Pedrinho, Rio dos Cedros e parte de Indaial, conforme se pode observar na Figura 1.

A SBH do rio Benedito tem $1.501 \mathrm{~km}^{2}$ e representa aproximadamente $10 \%$ da Bacia Hidrográfica do rio Itajaí. É uma das menores sub-bacias desta bacia, no entanto, o Inventário Hidrelétrico realizado em 1994 pela ELETROSUL, já apontava que dentre os três aproveitamentos hidrelétricos considerados economicamente viáveis na bacia do rio Itajaí, dois estavam na $\mathrm{SBH}$ do rio Benedito. Independente deste inventário fato é que atualmente encontram-se ali instalados e em operação, sete empreendimentos hidrelétricos enquadrados como CGH (Centrais Geradoras Hidrelétricas) e PCH (Pequenas Centrais Hidrelétricas).

Definida a área de estudo e tendo como referência estudos similares (Becker e Guadagnin, 2001; Fepam/ RS, 2003; Soma, 2002; Prosul/RTK, 2002-2003), elaborou-se uma lista de critérios ambientais relacionados aos temas: Ecossistema Terrestre, Ictiofauna, Uso Antrópico e Quantidade e Qualidade da Água.
Desta lista, alguns critérios não foram possíveis de ser trabalhados na SBH do rio Benedito, tais como os critérios de qualidade da água relacionados a análise do potencial de estratificação térmica dos reservatórios e potencial de eutrofização, pela indisponibilidade de dados, ou por não se adequarem aos objetivos deste estudo. Elaborou-se na sequência uma nova lista de critérios, denominada Lista de Critérios Ambientais para a SBH do rio Benedito que procura contemplar os dados existentes na bacia, conforme Quadro 1.

Selecionados os critérios ambientais, estes passaram por uma caracterização, geração de mapas temáticos básicos, definição de valores para geração do mapa de fragilidade para cada critério ambiental, cruzamento destes dados, para finalmente se efetuar a geração do mapa de criticidade da $\mathrm{SBH}$ do rio Benedito.

Para geração dos mapas base, foi utilizado o programa computacional ArcMap 9.2, extensões Spatial analyst e 3D Analyst.

Como base cartográfica, foram utilizadas as cartas do Mapeamento Sistemático Brasileiro (IBGE) na escala de 1:50.000, projeção UTM e Datum SAD-69, fuso 22. Os mapas em formato raster (fragilidade e de criticidade), possuem resolução espacial de 30 metros.

Quanto aos mapas temáticos básicos (hidrografia, declividade, vegetação original, uso do solo, zonas ur-

Quadro 1

LISTA DE CRITÉRIOS AMBIENTAIS PARAA SBH DO RIO BENEDITO.

\begin{tabular}{|c|c|c|c|}
\hline \multicolumn{4}{|c|}{ Critérios Ambientais } \\
\hline Ecossistema Terrestre & $\begin{array}{l}\text { Ecossistema Aquático } \\
\text { (Ictiofauna) }\end{array}$ & Usos Antrópicos & $\begin{array}{c}\text { Quantidade e Qualidade } \\
\text { da Água }\end{array}$ \\
\hline $\begin{array}{l}\text { Espacialização de Unidades } \\
\text { de Conservação } \\
\text { (Mapa 1) }\end{array}$ & $\begin{array}{l}\text { Classificação por diferentes } \\
\text { hábitats e presença de matas } \\
\text { ciliares (Mapa 4) }\end{array}$ & $\begin{array}{l}\text { Identificação e localização } \\
\text { de zonas urbanas e núcelos } \\
\text { populacionais no meio rural } \\
\text { (Mapa 5) }\end{array}$ & $\begin{array}{l}\text { Parâmetros de qualidade da } \\
\text { água } \\
\text { DBO (Mapa 7) } \\
\text { Turbidez (Mapa 8) } \\
\text { Coliforme Fecais (Mapa 9) }\end{array}$ \\
\hline $\begin{array}{l}\text { Áreas de remanescentes } \\
\text { florestais (Mapa 2) }\end{array}$ & $\begin{array}{l}\text { Conservação de rios repre- } \\
\text { sentativos sem barramentos }\end{array}$ & $\begin{array}{l}\text { Áreas de Interesse Turístico } \\
\text { e Paisagístico } \\
\text { (Mapa 6) }\end{array}$ & $\begin{array}{l}\text { Enquadramento dos cursos } \\
\text { da água (Mapa 10) }\end{array}$ \\
\hline \multirow[t]{2}{*}{$\begin{array}{l}\text { Corredores Ecológicos } \\
\text { (Mapa 3) }\end{array}$} & & & $\begin{array}{l}\text { Disponibilidade de água } \\
\text { levando em consideração o } \\
\text { Plano de Bacia (Mapa 11) }\end{array}$ \\
\hline & & & $\begin{array}{l}\text { Declividade } \\
\text { (Mapa 12) }\end{array}$ \\
\hline
\end{tabular}


banas, qualidade de água, enquadramento dos cursos de água, disponibilidade hídrica), foram utilizados aqueles desenvolvidos pelo Comitê do Itajaí. Posteriormente, estes mapas foram recortados para a área de estudo utilizando a ferramenta Clip do ArcMap.

Em seguida, conforme consta do Quadro 2, cada entidade dos mapas (Mapa 1 (um) a 12 (doze)) que constam das Figuras 3 à 10 situadas ao final do texto, recebeu um valor, conforme segue: Valor 0 (zero), para áreas onde a fragilidade ambiental não permite a implantação de empreendimentos hidrelétricos, denominada Zona de exclusão. Valor 1 (um), para áreas de baixa fragilidade ambiental, ou seja, áreas onde não existe restrição para a implantaçao dos empreendimentos. Valor 2 (dois), para áreas de média fragilidade ambiental, ou seja, pode ser exigido estudos detalhados. Valor 3 (três), para as áreas de alta fragilidade ambiental, zonas estas onde deverão ser elaborados estudos mais detalhados. Estes valores foram atribuídos levando em consideração referências bibliográficas que tratam de pesquisas pertinentes ao tema, experiência do pesquisador relativa ao ambiente e local da pesquisa, além de subordinação e adequaçao a legislação vigente.

Quadro 2

VALORES ATRIBUIIDOS AOS MAPAS TEMÁTICOS BÁSICOS

\begin{tabular}{|l|l|l|l|l|l|}
\hline \multicolumn{1}{|c|}{ Nome do mapa } & \multicolumn{4}{|c|}{ Valores } \\
\hline Espacialização de Unidades de Conservação & 0 & 1 & 2 & \\
\hline Áreas de Remanescentes Florestais & & 1 & 2 & \\
\hline Corredores Ecológicos & & 1 & 2 & \\
\hline $\begin{array}{l}\text { Classificação por diferentes hábitats } \\
\text { e presença de matas ciliares }\end{array}$ & 0 & 1 & 2 & 3 \\
\hline $\begin{array}{l}\text { Zonas Urbanas e Núcleos populacionais } \\
\text { distribuídos no meio rural }\end{array}$ & 0 & 1 & 2 & \\
\hline Áreas de interesse turístico e paisagístico & & 1 & 2 & \\
\hline Parâmetro de qualidade da água (DBO) & & 1 & 2 & \\
\hline Parâmetro de qualidade da água (turbidez) & & 1 & & \\
\hline $\begin{array}{l}\text { Parâmetro de qualidade da água } \\
\text { (coliformes fecais) }\end{array}$ & & 1 & 2 & \\
\hline Enquadramento dos cursos de água & 0 & 1 & & \\
\hline $\begin{array}{l}\text { Disponibilidade de água levando em consi- } \\
\text { deração o Plano de Bacia }\end{array}$ & & 1 & 2 & 3 \\
\hline Declividade & & 1 & 2 & 3 \\
\hline
\end{tabular}

Estes valores foram atribuídos para um projeto de pesquisa eminentemente acadêmico. No caso do estabelecimento de critérios ambientais para um modelo passível de ser aplicado em uma bacia hidrográfica, faz-se necessária uma equipe técnica multidisciplinar, para dar maior consistência aos valores propostos, respeitando as peculiaridades do local, tendo em vista que estes valores são de aplicaçao genérica.

Ao adotar o equacionamento produtório dos mapas, o objetivo foi atribuir valores mais altos às zonas de alta fragilidade. Quando se adota tal equacionamento, é possível tornar mais restritivas as áreas que foram valoradas em 3 (três) e 2 (dois), sendo as mesmas mais frágeis sob o ponto de vista ambiental. Outra vantagem do equacionamento produtório é a atribuição do valor 0 (zero) para as áreas de exclusão, pois este se mantém no resultado do produto (multiplicação).

Para realizar o cruzamento entre as informaçóes dos diversos mapas, estes foram convertidos para raster, utilizando a coluna dos valores para atribuir informaçóes aos pixels. O tamanho do pixel utilizado foi de trinta metros.

Para calcular o índice de criticidade ambiental, utilizando a ferramenta raster calculator do ArcMap, foi adotada a fórmula demonstrada na Figura 2:

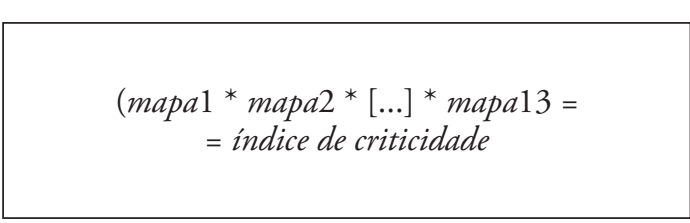

FIGURA 2. Fórmula de apuraçao do índice de criticidade para a SBH do rio Benedito

O equacionamento produtório, ou seja, esta multiplicação gerou um mapa cujo valores variaram de 1 (um) a 216 (duzentos e dezesseis), sendo divididos em três classes, denominadas Zonas de Criticidade. A primeira denomina-se Zonas de exclusão, onde o valor atribuído é zero. A segunda, Zonas de baixa criticidade, cujos valores variaram de 1 (um) a 4 (quatro) ficando abaixo ou igual a média, e a terceira, Zonas de estudos detalhados, para as áreas em que os pixels variaram de 5 (cinco) a 216 (duzentos e dezesseis) onde os valores ficam acima da média. 


\section{RESULTADOS E DISCUSSÃO}

Dentre os resultados da pesquisa tem-se a descrição de 12 (doze) critérios ambientais, gerando para cada critério 1 (um) mapa de fragilidade ambiental e ao final a elaboração do mapa de criticidade ambiental da SBH do rio Benedito.

Iniciando pelos critérios relacionados ao Ecossistema Terrestre tem-se a Espacialização das Unidades de Conservação existentes na SBH do rio Benedito. Da análise da Figura 3, que apresenta o Mapa de Espacialização das Unidades de Conservação na área objeto de estudo, verifica-se a existência da Reserva Biológica Estadual do Sassafrás (REBIO do Sassafrás), dividida em duas glebas, uma situada no Município de Doutor Pedrinho e outra situada entre os municípios de Doutor Pedrinho e Benedito Novo. Por se tratar de uma Unidade de Conservação de Proteção Integral, na elaboração do mapa de fragilidade ambiental decidiu-se considerar tal área como zona de exclusão de empreendimentos hidrelétricos

Como não se identificou, no ato normativo de criação desta Unidade de Conservação, qualquer definição da área de abrangência da zona de amortecimento, optou-se pela aplicação da Resolução CONAMA no13/90, que estabelece dez quilômetros de raio partindo dos limites da Unidade de Conservação. Assim, para fins de realizaçáo do mapa de fragilidade ambiental, atribuiu-se valor 2 (dois) para a zona de amortecimento $(10 \mathrm{Km})$ da REBIO do Sassafrás; e valor 1 (um) para as áreas onde não existem restriçóes para implantaçáo de empreendimentos hidrelétricos.

Outro critério adotado neste estudo e relacionado ao Ecossistema Terrestre, foi a identificação das Áreas de Remanescentes Florestais na SBH do rio Benedito. A expansão agrícola e o crescimento urbano provocaram uma fragmentação da vegetação nativa, gerando muitas vezes danos irreverssíveis. Segundo Viana et al. (1992), os principais fatores que afetam a dinâmica de fragmentos florestais são: tamanho, forma, grau de isolamento, tipo de vizinhança e histórico de perturbaçóes. Esses fatores apresentam relaçóes com fenômenos biológicos que afetam a natalidade e a mortalidade de plantas como, por exemplo, o efeito de borda, a deriva genética e as interaçóes entre plantas e animais.

Segundo este mesmo autor, a distribuição das classes de tamanho dos fragmentos na paisagem é um elemento importante para o desenvolvimento de estratégias para a conservação da biodiversidade. Além deste elemento, a definição de fragmentos prioritários para a conservação deve incluir o grau de isolamento, forma, nível de degradação e risco de perturbação.

O grau de isolamento de um fragmento afeta o fluxo gênico entre os mesmos e a sustentabilidade de populaçóes naturais. Os limites geográficos para a definição de estratégias conservacionistas devem considerar unidades da paisagem homogêneas quanto às características de fragmentação dos ecossistemas naturais.

Para fins de realizaçáo do mapa de fragilidade ambiental, optou-se por associar os remanescentes florestais acima de 100 ha atribuindo valor 2 (dois) para estas áreas, onde a construção de empreendimentos hidrelétricos fica condicionada à realização de estudos ambientais mais detalhados, e para as áreas de remanescentes florestais com menos de 100 ha e outros usos do solo, onde não existe restrição, atribuiu-se valor 1 (um), conforme Figura 4. Destaca-se a dificuldade encontrada, para a definiçáo destes valores como sendo os ideais, tendo em vista, a nao existência de uma equipe multidisciplinar que pudesse corroborar com a definição do tamanho adequado do fragmento.

Um terceiro critério relacionado ao Ecossistema Terrestre e que deve ser considerado no licenciamento de empreendimentos hidrelétricos, é a existência de Corredores Ecológicos, que podem ser definidos como, "a porção do sistema natural ou semi-natural, ligando Unidades de Conservação, que possibilitam entre elas o fluxo de genes e o movimento da biota, facilitando a dispersâo de espécies e a recolonização de áreas degradadas, bem como a manutenção de populaçóes que demandam para sua sobrevivência áreas com extensão maior do que aquela das unidades individuais (Lei no 9.985/00, art. 2º, IX).

$\mathrm{Na}$ área objeto de estudo, não se identificou a institucionalizaçáo de corredores ecológicos, no entanto, da análise do mapa de espacializaçáo das Unidades de Conservação evidencia-se a existência de condiçôes propícias para a criação de um corredor ecológico que faça a conectividade entre as duas glebas da Reserva Biológica do Sassafrás, situadas na mesma sub-bacia e a Reserva Indígena Duque de Caxias, situada na bacia contígua, na linha do divisor de águas que também faz a divisa dos municípios de Doutor Pedrinho e Ibirama.

Para a definição desse corredor ecológico utilizou-se como critério a distância de $2 \mathrm{Km}$ a partir do divisor de águas da SBH do rio Benedito, no trecho que liga as duas glebas da Reserva Biológica Estadual do Sassafrás, por se tratar de uma área de remanes- 
centes florestais contínua. Neste critério também houve dificuldade para determinar a extensão da largura do corredor ecológico, em virtude de não se ter uma equipe multidisciplinar que pudesse avaliar a adequação da extensão proposta.

Para a realização do mapa de fragilidade ambiental optou-se por atribuir valor 2 (dois) para a área situada no interior do corredor ecológico, onde a construção de empreendimentos hidrelétricos fica condicionada a realização de estudos ambientais mais detalhados, e para as demais áreas onde não existe restrição atribui-se valor 1 (um), Figura 5.

$\mathrm{Na}$ sequência foram analisados os critérios relacionados ao Ecossistema Aquático. Dentre os poucos critérios ambientais relacionados a este tema, voltados mais especificamente para a Ictiofauna, passíveis de serem mensurados e aplicados ao modelo de geoprocessamento, tem-se a classificação por diferentes hábitats e a presença de matas ciliares.

Do ponto de vista da biologia de peixes, a mata ciliar possui as funções ecológicas de proteção estrutural dos hábitats, regulagem do fluxo e vazão de água, abrigo e sombra, manutenção da qualidade da água, filtragem de substâncias que chegam ao rio, e fornecimento de matéria orgânica e substrato de fixação de algas e perifíton.

Os cursos de água de cabeceiras são riachos pequenos e frágeis, onde a cobertura vegetal das margens é de extrema importância para a sua conservação, pois evita a erosão dos solos adjacentes, impedindo a sedimentação ou assoreamento do leito do rio.

Numa relação mais direta, observa-se que rios margeados por vegetação nativa, fornecem grande variedade de itens alimentares, principalmente insetos e vegetais superiores. Estes itens são de grande importância na sobrevivência e na etologia de peixes tropicais de água doce (Lowe-McConnel, 1987, apud, Rodrigues e Leitão Filho, 2000).

Em virtude da importância da mata ciliar para a manutenção do equilíbrio ecológico, em especial dos sistemas aquáticos, a legislação ambiental brasileira lhe confere proteção jurídica específica, por meio da Lei no 4.771/65 (Código Florestal), em seu art. 2º que trata das Área de Preservação Permanente - APP.

Da análise do uso do solo nas áreas de APP (realizado em escala 1:50.000) ao longo dos cursos da água da $\mathrm{SBH}$ do rio Benedito, verifica-se que nos rios de primeira, segunda e terceira ordem há um predomínio de floresta, capoeira e capoeirinha. Já nos rios de sexta e sétima ordem, com declividade variando de $0^{\circ}$ a $5^{\circ}$ prevalecem as atividades de rizicultura e áreas urbanas.

Para fins de realização do mapa de fragilidade ambiental, optou-se por privilegiar a proteção dos cursos de água de cabeceiras (primeira, segunda e terceira ordem), onde a vegetação tem maior contato com os sistemas aquáticos e, portanto, exerce maior influência na manutenção da integridade biótica e abiótica desses sistemas, considerando-os zonas de exclusão de empreendimentos hidrelétricos.

Já nos cursos de água enquadrados como de quarta e quinta ordem verifica-se uma mescla de áreas de mata ciliar bem conservadas e áreas com diferentes tipos de uso, levando a atribuição de valor 3 (três), onde a construção de empreendimentos hidrelétricos fica condicionada a realização de estudos ambientais mais detalhados, visto a fragilidade ambiental ainda ser alta.

Quanto aos cursos de água enquadrados como de sexta e sétima ordem, atribuiu-se valor 2 (dois), onde não existe restrição, não porque a vegetação ciliar seja menos importante nestas áreas, mas em razão da implantaçáo do novo equilíbrio dinâmico e delicado, oriundo do intenso processo de antropização que ali se instaurou. Para as áreas onde não existe restrição relacionada a este critério atribui-se valor 1 (um), conforme se depreende da análise da Figura 6.

Outro critério relacionado com o Ecossistema Aquático, especialmente com a Ictiofauna é a conservação de rios representativos sem barramentos.

De acordo com os estudos elaborados pela Fepam (2001), para o estabelecimento de diretrizes regionais para o licenciamento ambiental de empreendimentos hidrelétricos na bacia do Taquari Antas - RS, verificou-se que para a conservação da biota aquática da bacia hidrográfica, seria importante conservar sem barragens pelo menos um rio nas bacias de planalto e nas bacias de encostas, com o objetivo de assegurar amostras dos regimes hidrológicos distintos e prováveis diferenças ecológicas em termos de hábitats para peixes.

Apesar da imensa rede hídrica sul-americana, bem como do Brasil, poucos são os estudos (Haro et al., 1991; Sabino e Zuanon, 1998; Miserendino, 2001) que tratam da diversidade, composição e abundância da comunidade aquática, considerando-se as dimensôes longitudinal, lateral, vertical e temporal dos cursos da água. Mais escassos ainda, são aqueles trabalhos dedicados aos riachos localizados na Floresta Pluvial Atlântica (Sabino e Castro, 1990; Uieda et. al., 2001; Mazzoni e Lobón-Cerviá, 2000). 
Segundo Becker e Guadagnim (2001), existe uma forte variação de tipos e quantidade de habitat entre rios de tamanhos diferentes, mesmo quando localizados dentro da mesma regiáo. Rios de diferentes tamanhos representam diferentes habitats para peixes devido à correlação de tamanho com vazão, profundidade, disponibilidade de refúgios, tipos e quantidades relativas de meso e microhabitats. Em conseqüência, em diferentes tamanhos de rios espera-se encontrar diferenças na composição de riqueza de espécies, estrutura trófica e abundância de indivíduos, ou seja, quanto maior o número de ordens que constituem determinado rio, presume-se a existência de um ecossistema aquático mais complexo e diversificado, portanto, suscetível de maior proteção pela sua importância ecológica.

Em virtude do exposto, verifica-se a importância de se manter sem barragens um rio representativo de curso baixo, médio e alto na SBH do rio Benedito, tendo por objetivo, possibilitar o desenvolvimento de estudos de longa duração e em situaçôes de contraste do estado de conservaçáo dos sistemas aquáticos, permitir comparações e o estabelecimento de padróes de resposta destes ambientes às alteraçóes impostas. Neste estudo foi possível identificar as diferentes ordens dos rios que compóem o sistema hidrográfico da bacia do Benedito. No entanto, não foi possível identificar quais destes rios poderiam ser escolhidos como representativos, ante a impossibilidade de se reunir equipe técnica multidisciplinar que fizesse tal seleção, por este motivo, não foi elaborado o mapa de fragilidade relativo a este critério.

Quanto aos critérios relacionados aos Usos Antrópicos, primeiramente foram identificadas e localizadas as zonas urbanas e núcleos populacionais distribuídos no meio rural. No Brasil a Lei no 5.172/66 (Código Tributário Nacional), estabelece que zona urbana é aquela definida em Lei municipal; observado o requisito mínimo da existência de melhoramentos indicados em pelo menos dois dos incisos seguintes, construídos ou mantidos pelo poder público: I) meio fio ou calçamento, com canalização de águas pluviais; II ) abastecimento de água; III ) sistema de esgotos sanitários; IV ) rede de iluminaçáo pública, com ou sem posteamento para distribuição domiciliar; V ) escola primária ou posto de saúde a uma distância máxima de três quilômetros do local considerado.

$\mathrm{Na}$ área de estudo, percebe-se que a ocupação humana ocorre preferencialmente nas proximidades dos cursos d'água, com a existência de uma expressiva zona urbana nos municípios de Timbó e Indaial (par- te que integra a sub-bacia) e zonas urbanas menores mesclando-se com núcleos populacionais rurais nos demais municípios da sub-bacia.

Segundo Cruz; Silveira e Cruz (2005), a localização geográfica de sedes municipais e de localidades rurais constitui-se em uma das possíveis restriçôes para o posicionamento e desenvolvimento de barramentos. De forma a contemplar possíveis expansóes, devem ser adotadas "áreas de exclusão" no entorno dos pontos de localização de áreas urbanizadas. Este critério também poderia ter uma definição mais precisa e consistente, caso tivesse uma equipe multidisciplinar para ajustar os poucos valores encontrados na escassa bibliografia que tratava do assunto.

Para fins da realização do mapa de fragilidades da $\mathrm{SBH}$ do rio Benedito, as áreas urbanas e núcleos populacionais distribuídos no meio rural, foram consideradas zonas de exclusão de empreendimentos hidrelétricos. Atribuiu-se valor 2 (dois) para o entorno das áreas urbanizadas, num raio de $2,5 \mathrm{Km}$ para sedes municipais e $500 \mathrm{~m}$ para os núcleos populacionais distribuídos no meio rural, onde deverão ser realizados estudos ambientais mais detalhados. Para as áreas onde não existe restrição atribui-se valor 1 (um), conforme Figura 7.

O último critério que integra os Usos Antrópicos utilizado neste trabalho, são as Áreas de Interesse Turístico e Paisagístico.

$\mathrm{Na}$ sub-bacia do rio Benedito, foi possível identificar a presença de Zonas de Interesse Ambiental e Turístico (ZIAT) previstas nos Planos Diretores dos municípios de Rio dos Cedros, Timbó e Benedito Novo, todos eles aprovados no ano de 2006.

No Município de Rio do Cedros, foram criadas duas Áreas de Interesse Turístico: 1) Área Especial de Interesse Turístico e Ambiental do Pinhal (AEITA - Pinhal); 2) Área Especial de Interesse Turístico e Ambiental do Rio Bonito (AEITA - Rio Bonito).

As AEITAs mencionadas acima, correspondem às áreas de contribuição das barragens do Pinhal e do Rio Bonito. De acordo com o referido Plano Diretor, tais áreas serão objeto de estudo ambiental específico o qual, definirá parâmetros de uso e ocupação de acordo com a capacidade de suporte das mesmas.

No Plano Diretor do Município de Timbó foi identificada a Zona de Interesse Turístico, formada pelos morros Arapongas e Azul, com potencial turístico, desde que desenvolvida de maneira sustentável, garantindo a preservação das características naturais e do patrimônio natural. 
No Plano Diretor do Município de Benedito Novo, também foram identificadas Zonas de Interesse Ambiental e Turístico (ZIAT). As ZIATs são áreas que devido a sua localização e atributos naturais devem ser destinadas preferencialmente ao uso turístico, incentivando sempre que possível o turismo ecológico de baixo impacto.

Pela leitura das normas municipais expostas evidenciou-se o interesse do poder público em proteger determinadas áreas dos municípios com forte potencial turístico. Por si só, a criação destas áreas a princípio, não é um impeditivo legal para a implantaçáo de empreendimentos hidrelétricos, mas apenas uma condicionante que deverá ser levada em consideração quando da realização dos estudos ambientais para fins de licenciamento, por isso definiu-se valor 2 (dois) para estas áreas. Esta condicionante tem por objetivo compatibilizar o empreendimento com a vocação turística da área, de forma que a mesma deverá ser contemplada quando da elaboraçáo do Termo de Referência dos Estudos Ambientais. Para as demais áreas onde não existe esta condicionante, definiu-se o valor 1 (um), Figura 8.

Quanto aos critérios relacionados à Quantidade e Qualidade da Água utilizados neste trabalho, pesquisou-se primeiramente os parâmetros de qualidade da água. A qualidade da água pode ser representada por diversos parâmetros que traduzem as principais características físicas, químicas e biológicas. As características desejáveis da água dependem do uso que dela será feito.

A avaliação da qualidade da água tem por objetivo agrupar um grande número de informações em uma forma que possibilite pronta interpretação e reconhecimento das tendências ao longo do tempo e do espaço. Segundo Bollman e Marques (2000, apud Pinheiro, 2004), os indicadores da variação da qualidade da água são considerados uma aproximação válida das alteraçóes ambientais.

$\mathrm{Na}$ área de estudo, os dados disponíveis sobre qualidade de água foram extraídos do "Plano de Recursos Hídricos da Bacia Hidrográfica do Rio Itajaí: Fase A - Diagnóstico e Prognóstico" (Comitê do Itajaí, 2006), extraído de diferentes estudos (Locatelli, 2003; Pinheiro, 2002; Ortiz, 2003). Dentre estes dados foi possível identificar apenas um parâmetro para cada uma das características da água: físico (Turbidez), químico (DBO) e biológico (Coliformes Fecais).

Com relação à $\mathrm{DBO}$, as análises demonstraram que este parâmetro encontra-se dentro dos padróes de qualidade estabelecidos na Resolução CONAMA no 357/05, nos três pontos de coleta situados à montante da cidade de Timbó, e não conforme com os referidos padróes, somente no ponto situado à jusante da mesma cidade.

Com relação à Turbidez, nos pontos de coleta estudados, as análises demonstraram que este parâmetro encontra-se dentro dos padróes de qualidade estabelecidos na Resolução CONAMA no 357/05.

Com relação aos Coliformes Fecais, nos pontos de coleta situados nos municípios de Doutor Pedrinho (1), Benedito Novo (2) Rio dos Cedros (1) e Timbó (6), as análises demonstraram que este parâmetro encontra-se fora dos padróes de qualidade estabelecidos na Resolução CONAMA no 357/05 em todos os pontos de coleta.

Assim para fins de realização do mapa de fragilidade ambiental decidiu-se aplicar valor 2 (dois) nos pontos onde o parâmetro de qualidade de água medido náo atende ao padrão estabelecido pela Resolução CONAMA no 357/05, enquanto que nos pontos onde o parâmetro de qualidade de água medido atende ao padrão estabelecido pela Resolução CONAMA no 357/05 o valor é 1 (um). Como as informaçôes existentes sobre os parâmetros indicados são pouco expressivas em relação a área de abrangência e periodicidade das coletas, e embora tenham sido produzidos os respectivos mapas, para fins deste artigo, decidiu-se omitir os mapas e apresentar apenas os dados descritivos. Destaca-se que a maior dificuldade encontrada na aplicação deste critéirio, foi a existência de dados pontuais, o que não permitiu identificar e demonstrar as características de um trecho ou área demarcada por um polígono.

Um segundo critério relacionado à Quantidade e Qualidade de Água é o Enquadramento dos Cursos de água. Segundo o enquadramento dos cursos de água do Estado de Santa Catarina, estabelecido por meio da Portaria SEPLAN/CG/SC n ${ }^{\circ} 24 / 79$, na SBH do rio Benedito foram identificados rios de classe 1 e classe 2. No entanto, há que se ter em conta que o enquadramento existente atualmente no Estado de Santa Catarina, expresso por meio da Portaria retro-mencionada, fundamentou-se na Portaria GM $n^{\circ}$ 13/76 do Ministério do Interior, a qual estabelecia apenas quatro classes para as águas doces, classes 1, 2, 3 e 4. Sendo que os usos permitidos para os rios de classe 1, nos termos da Portaria GM n ${ }^{\circ}$ 13/76 correspondem atualmente aos usos permitidos para os rios de classe especial da Resolução CONAMA n ${ }^{\circ}$ 357/05. Assim, os rios enquadrados como classe 1 na $\mathrm{SBH}$ do rio Benedito, na verdade são aqueles de classe especial, voltados 
à preservação do equilíbrio natural das comunidades aquáticas e à preservação dos ambientes aquáticos em unidades de conservação de proteção integral. Tal assertiva pode ser comprovada pelo fato de os rios de classe $1 \mathrm{da}$ SBH do rio Benedito estarem situados justamente dentro de uma Unidade de Conservação de Proteção Integral, que é a REBIO do Sassafrás.

Verifica-se, portanto, a presença na área de estudo de rios enquadrados como classe 1 e classe 2 . Sendo considerados de classe 1 , o Rio Novo e seus afluentes e o Rio Forcação, contribuinte da margem direita do Rio Benedito e seus afluentes, todos os os dois situados no Município de Doutor Pedrinho, dentro da área da Gleba 1 da REBIO do Sassafrás, e, de classe 2, todos os demais cursos de água existentes na sub-bacia.

Para fins de realização do mapa de fragilidade ambiental, optou-se por consideradar como zona de exclusão de empreendimentos hidrelétricos os rios enquadrados como classe 1. Para os demais rios, todos enquadrados como classe 2 , onde náo existe restrição, definiu-se o valor 1 (um). Como os rios de classe 1 estáo situados dentro da Gleba 1 da REBIO do Sassafrás, já considerada zona de exclusão de empreendimentos hidrelétricos, decidiu-se omitir o mapa e apresentar apenas os dados descritivos.

O terceiro critério relacionado à Quantidade e Qualidade da Água levantado no trabalho foi a Disponibilidade de água levando em consideração o Plano de Bacia.

De acordo com a Lei ${ }^{\circ} 9.433 / 97$, em seu art. $6^{\circ}$, os planos de recursos hídricos $(\mathrm{PRH})$ são planos diretores que visam fundamentar e orientar a implantação da Política Nacional de Recursos Hídricos e o gerenciamento de recursos hídricos. Os planos serão concebidos por bacia hidrográfica, por Estado e para o País $\left(\operatorname{art.} 8^{\circ}\right.$ ). A Lei n ${ }^{\circ}$ 9.433/97 estabelece o conteúdo mínimo destes planos, que devem conter dentre outros, o balanço entre disponibilidades e demandas futuras dos recursos hídricos, em quantidade e qualidade, com identificação dos conflitos potenciais e estabelecer prioridades para outorga de direitos de usos de recursos hídricos.

Como na Bacia Hidrográfica do rio Itajaí, à qual pertence a SBH do rio Benedito já existe plano de recursos hídricos e critérios de outorga estabelecidos, os mesmos deverão ser considerados na elaboração do mapa de criticidade ambiental, quando se aborda o critério "quantidade de água disponível".

A partir da análise da disponibilidade na SBH do rio Benedito, verifica-se que a disponibilidade hídrica no alto curso, varia de 2.000 a $7.500 \mathrm{l} / \mathrm{s}$; no curso médio de 7.500 a $16.000 \mathrm{l} / \mathrm{s}$ e no baixo curso maior que 16.000 l/s. Resolveu-se atribuir valor 3 (três) para a menor disponibilidade de água por se tratar de uma restrição natural à implantação de empreendimentos hidrelétricos. Atribuiu-se valor 1 (um), para a maior disponibilidade de água por se tratar de uma variável favorável a realizaçáo destes empreendimentos, e valor 2 (dois) para disponibilidade média, conforme Figura 9.

O último critério relacionado à Quantidade e Qualidade da Água analisado foi a declividade. Em uma bacia hidrográfica a disponibilidade hídrica média, extraída de medidas de vazóes durante períodos hidrológicos longos, bem como as declividades encontradas em seu relevo, são variáveis importantes para subsidiar a elaboração de qualquer análise energética mais detalhada, possibilitando estimar parâmetros como potência, energia média e energia firme em uma área ou empreendimento. A energia firme de uma usina, é calculada em função da queda e da vazão média no local do aproveitamento, obtidas durante o período hidrológico crítico da bacia (Eletrosul, 1994), daí a importância de se levar em consideração este critério. Verifica-se que a $\mathrm{SBH}$ do rio Benedito compreende três patamares com características homogêneas. $\mathrm{O}$ primeiro patamar que ocupa em torno de $60 \%$ da SBH do rio Benedito localizada entre Sudoeste e Norte/Noroeste compóe-se de uma mescla de diferentes declividades. O segundo patamar ocupa em torno de $25 \%$ da sub-bacia, localizada entre Sudoeste/Nordeste, compóe-se de um relevo montanhoso com declividades variando entre $15^{\circ}$ e mais que $25^{\circ}$. O terceiro patamar, ocupa em torno de $15 \%$ da área, localizado na regiáo Leste da sub-bacia, compóe-se basicamente de áreas com declividade entre $0^{\circ}$ e $15^{\circ}$.

Atribuiu-se valor 3 (três) para as áreas com maior declividade e conseqüentemente maior fragilidade ambiental, valor 2 (dois) para as áreas de declividades médias variando de $15^{\circ}$ a $25^{\circ}$, e valor 1 (um) para as áreas mais planas onde a fragilidade ambiental é menor, conforme Figura 10.

Partindo dos mapas temáticos básicos gerados a partir da Lista de Critérios para a SBH do rio Benedito e consequente geração dos mapas de fragilidades, foi possível com auxílio da ferramenta computacional raster calculator do ArcMap, gerar o mapa de criticidade ambiental da $\mathrm{SBH}$ do rio Benedito (Figura 11 ), cujo cruzamento gerou valores de pixels que variaram de 1 (um) a 216 (duzentos e dezesseis), e também uma área de exclusão (zero). $\mathrm{O}$ valor 0 (zero) passou a ser denominado Zona de exclusão. 
Os valores dos pixels de 1 (um) a 216 (duzentos e dezesseis) foram divididos em duas Zonas. Foi denominado como Zona de baixa criticidade, às áreas cujos valores variaram de 1 (um) a 4 (quatro), que representam a média, e Zona de estudos detalhados, para as áreas em que os pixels variaram de 5 (cinco) a 216 (duzentos e dezesseis). Este mapa tem dentre as suas finalidades, demonstrar a criticidade da área de estudo para a implantação de empreendimentos hidrelétricos, além de desencadear novas discussôes sobre os critérios que foram adotados.

\section{CONCLUSÕES E RECOMENDAÇOES}

Da análise do mapa de criticidade ambiental da $\mathrm{SBH}$ do rio Benedito constante da Figura 11, é possível tecer as seguintes conclusóes:

Verificam-se zonas de exclusão bem definidas nas Unidades de Conservação, áreas urbanas, núcleos populacionais distribuídos no meio rural e nos cursos de água enquadrados como de primeira, segunda e terceira ordem. Com relação às áreas urbanas ressalta a primeira vista os centros urbanos de Timbó e Indaial, na seqüência, não tão expressivos, mas significativos, as sedes dos municípios de Rio dos Cedros, Benedito Novo, Doutor Pedrinho e Rodeio. Com relação aos cursos de água de primeira, segunda e terceira ordem, é possível verificar que os mesmos não se concentram apenas no alto curso e próximo aos divisores de água, mas encontram-se distribuídos de forma relativamente homogênea em toda a SBH do rio Benedito.

Quanto às zonas de estudos detalhados, que representam aproximadamente $40 \%$ da área da SBH do rio Benedito, é possível perceber que estas concentram-se, na região Centro-Oeste em direção a Noroeste e Norte, abrangendo os municípios de Rio dos Cedros, Doutor Pedrinho e parte de Benedito Novo. Os critérios que mais contribuíram para a formaçáo destas zonas foram, as áreas de interesse turístico e paisagístico, o corredor ecológico, a disponibilidade de água e a zona de amortecimento da Unidade de Conservação REBIO do Sassafrás. De forma que, na etapa de licença ambiental prévia (LP), onde normalmente se procedem os estudos de viabilidade ambiental do empreendimento hidrelétrico, Relatório Ambiental Preliminar (RAP), Estudo Ambiental Simplificado (EAS) ou Estudo de Impacto Ambiental (EIA), conforme o porte do empreendimento, o órgão ambiental deverá fazer constar no Termo de Referência dos respectivos estudos, a necessidade de uma análise mais detalhada em relação a estes critérios.
Quanto às zonas de baixa criticidade, que representam aproximadamente $50 \%$ da $\mathrm{SBH}$ do rio Benedito, é possível perceber que estas concentram-se na regiáo Sul/Sudeste e Centro-Leste. Os critérios que mais contribuíram para a formação destas zonas foram, disponibilidade hídrica e a declividade.

Embora dos 26 (vinte e seis) critérios identificados nos estudos pesquisados, apenas 12 (doze) tenham sido aplicados para a SBH do rio Benedito, ficou evidente que estudos semelhantes a este, poderão servir de suporte ao órgão ambiental para uma atuação pró-ativa, procurando evitar o licenciamento de atividades em áreas inadequadas, incorporando procedimentos de análise ambiental já nas etapas de planejamento a exemplo da Avaliação Ambiental Integrada (AAI) e da Avaliação Ambiental Estratégica (AAE).

Portanto, diante dos resultados obtidos no presente trabalho, pode-se afirmar que ele atingiu seu objetivo principal que era propor um mapa de criticidade ambiental, que poderá servir de modelo metodológico para ser levado em consideração pelo órgão ambiental, no processo de licenciamento de empreendimentos hidrelétricos.

Finalizando o presente estudo cumpre ainda fazer as seguintes recomendaçóes:

Que se efetuem maiores pesquisas com relação a ictiofauna, pois quanto a este critério, muito pouco foi possível encontrar de referência bibliográfica, sobretudo a respeito dos táxons na $\mathrm{SBH}$ do rio Benedito, e mesmo na bacia hidrográfica do rio Itajaí, não possibilitando, dentre outras comparaçóes analisar se existe alguma relação entre os táxons do rio Itajaí e os existentes nas áreas de cabeceiras do rio Benedito e Cedros.

E por fim, deixar claro a imprescindível necessidade da existência de uma equipe técnica multidisciplinar, proporcionando maior consistência, além de um adequado dimensionamento aos parâmetros aplicados aos diferentes critérios analisados, contribuindo para geração de um estudo que possa analisar uma bacia hidrográfica de maneira holística, sustentável e estratégica.

\section{AGRADECIMENTO}

Ao Prof. Dr. Julio César Refosco e ao Mestre Odirlei Fistarol, pelo auxílio na realização dos mapas, bem como, a Universidade Regional de Blumenau FURB e a CAPES, através do Programa de Suporte à Pós Graduação de Instituiçóes de Ensino - PROSUP, pela bolsa de pesquisa recebida. 
Fernandes, O.; Bohn, N. ミ Modelo para aplicação de critérios ambientais para licenciamento de empreendimentos hidrelétricos...

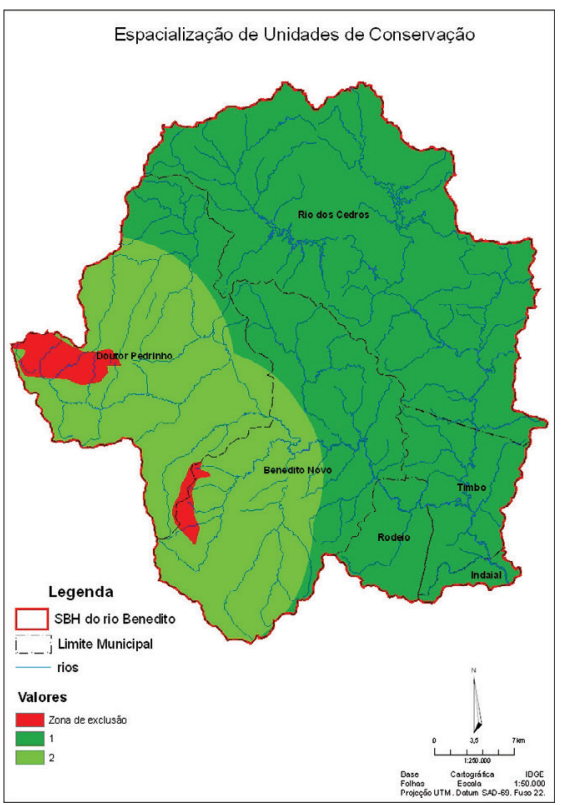

FIGURA 3. Espacialização de Unidades de Conservação na SBH do rio Benedito Fonte: Fernandes, 2008.

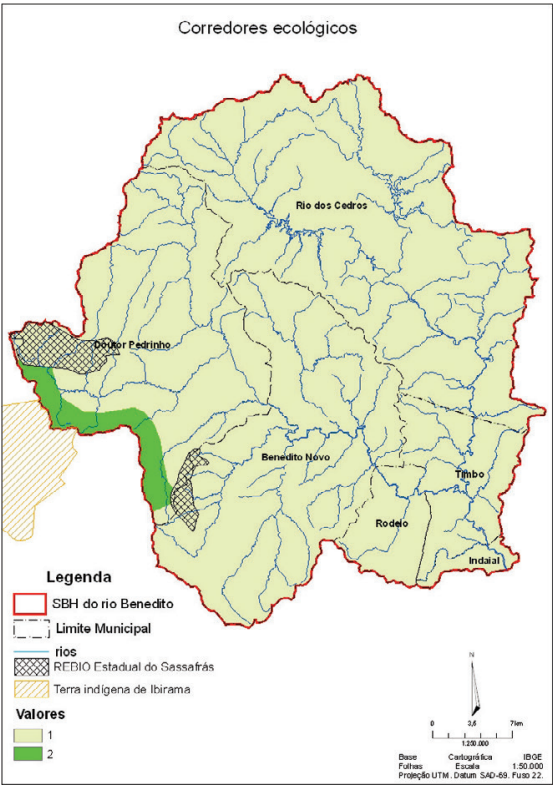

FIGURA 5. Corredores ecológicos na SBH do rio Benedito

Fonte Fernandes , 2008

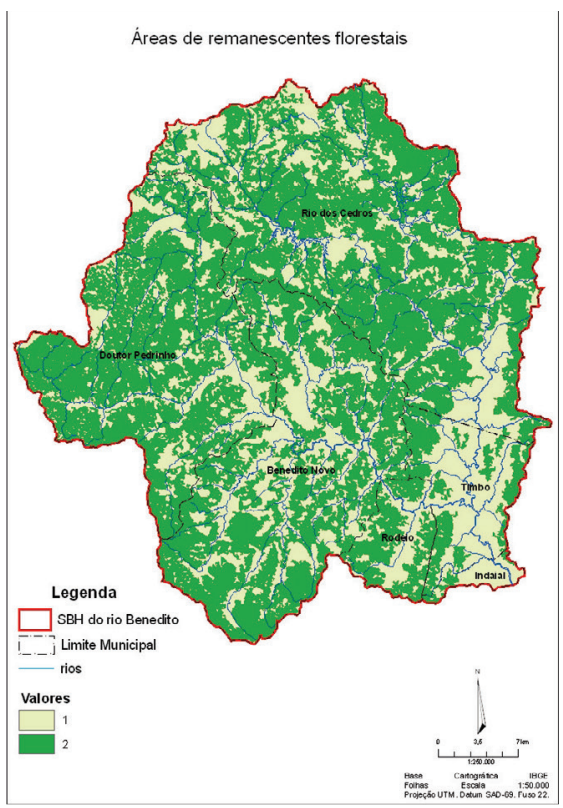

67

FIGURA 4. Área de remanescentes. Florestais da SBH do rio Benedito.

Fonte: Fernandes, 2008.

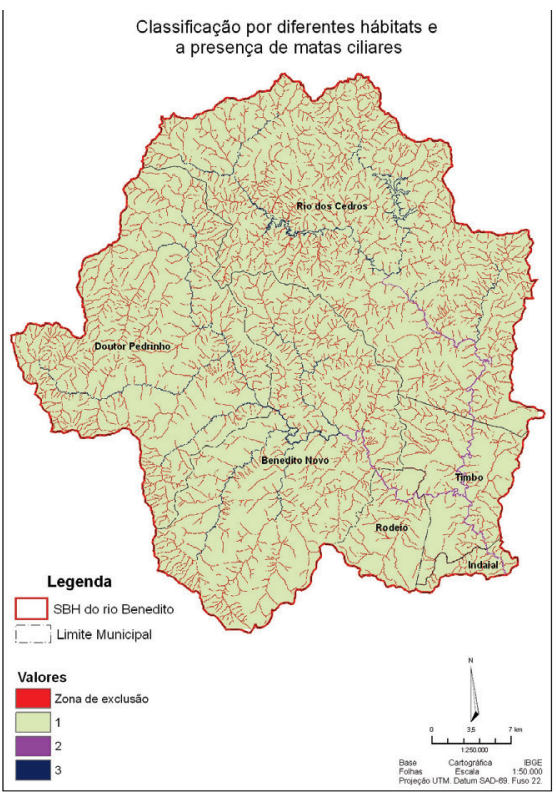

FIGURA 6. Classificação do rio por diferentes habitats e presença de matas ciliares

Fonte: Fernandes, 2008. 


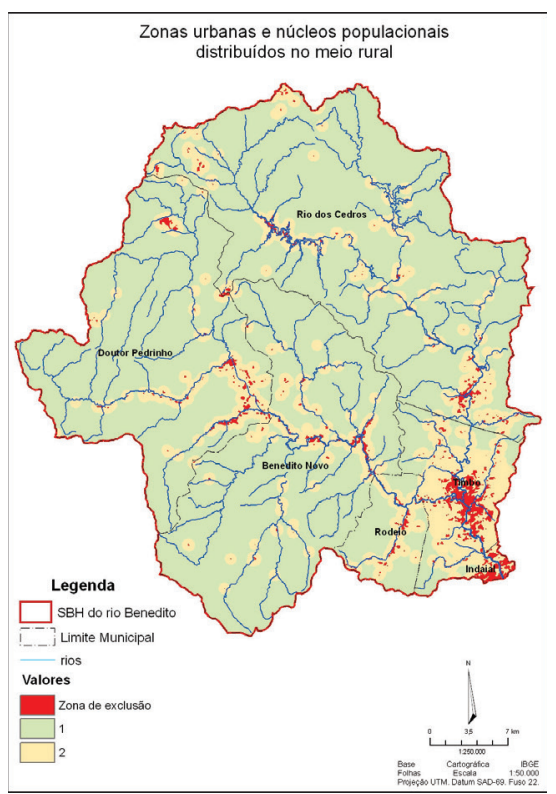

FIGURA 7. Identificação e localização de zonas urbanas e núcleos populacionais distribuídos no meio rural na SBH do rio Benedito.

Fonte: Fernandes, 2008.

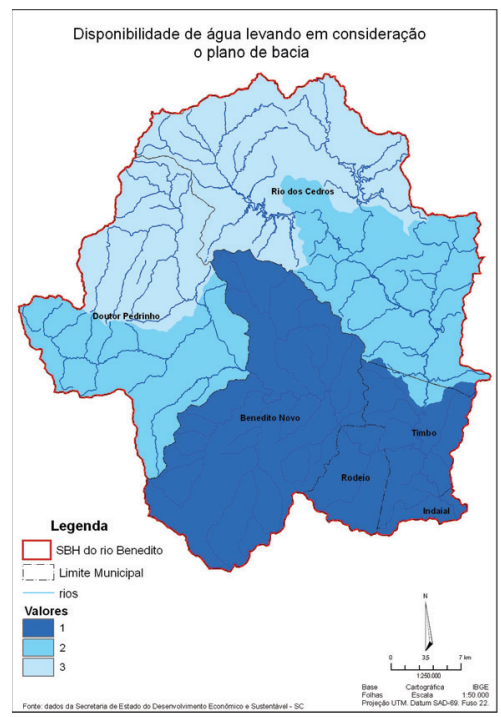

FIGURA 9. Disponibilidade de água na SBH do rio Benedito levando-se em consideração dados do Plano de Bacia.

Fonte: Fernandes, 2008.

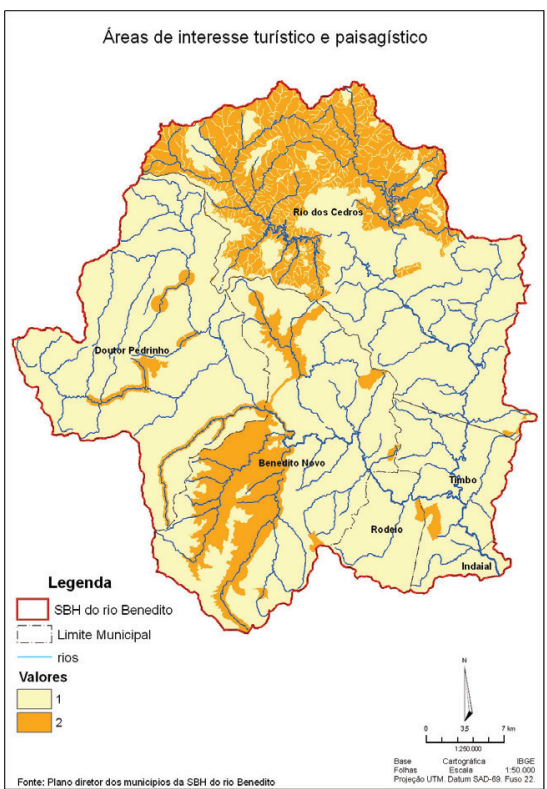

FIGURA 8. Áreas de interesse turístico e paisagístico na SBH do rio Benedito.

Fonte: Fernandes, 2008.

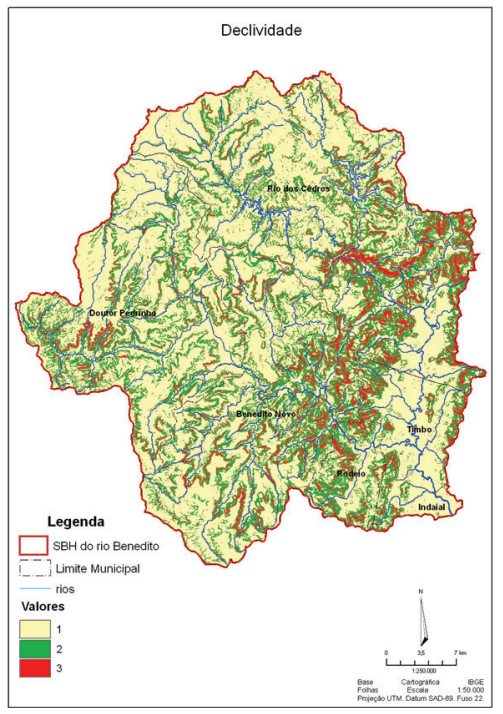

FIGURA 10. Declividade na SBH do rio Benedito. Fonte: Fernandes, 2008. 
Fernandes, O.; Bohn, N. $\approx$ Modelo para aplicação de critérios ambientais para licenciamento de empreendimentos hidrelétricos...

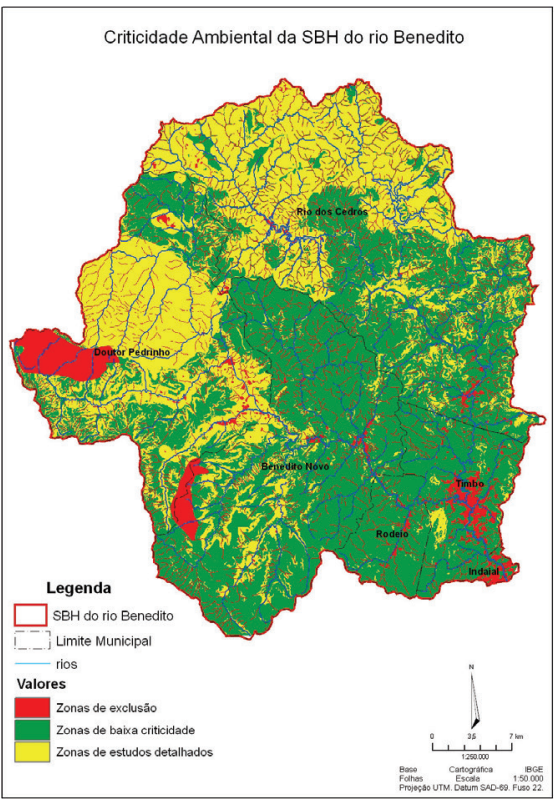

\section{FIGURA 11. Mapa de Criticidade ambiental da SBH do rio Benedito. \\ Fonte: Fernandes, 2008.}

\section{Referências}

AGMARN - Agência Goiana de Meio Ambiente e Recursos Naturais (2004). Termo de ajustamento de conduta para estudo integrado de bacia hidrográfica no Estado de Goiás. http://www.agenciaambiental.go.gov.br/site/estudosprojetos/pag_eibh.php Acesso em: 8/2/2006.

ARMOUR, A. (1991) Impact assesment and the planning process. In: Impact Bulletin, v.9, pp.27-33.

BECKER, G.; GUADAGNIN, D. (2001). Análise dos impactos regionais potenciais dos múltiplos barramentos de rios na bacia Taquari-Antas sobre a biodiversidade e orientação para o processo de licenciamento. Porto Alegre. (não publicado)

COMITÊ DO ITAJAí (2006) Plano de Recursos Hídricos da Bacia Hidrográfica do Rio Itajaí: Fase A - Diagnóstico e Prognóstico. http:/l www.comiteitajai.org.br Acesso em: 8/2/2006.

CRUZ, J. C.; SILVEIRA, G. L. da; CRUZ, R. C. (2005). Estudos preliminares. In: Seleção ambiental de barragens: análise de favorabilidades ambientais em escala de bacia hidrográfica. SILVEIRA, G. L. e CRUZ, J. C. (orgs.) Santa Maria: Ed. UFSM.

DARRIEUTORT, J. P. (1991). Les evaluations environmentales des politiques, plans et programes: aménagement et nature. v.102, Part Eté, pp. 8-9.

ELETROBRÁS (1997). Manual de inventário hidrelétrico de bacias hidrográficas da ELETROBRÁS. Rio de Janeiro.

ELETROSUL (1994). Estudo de inventário hidroenergético da bacia do rio Itajaí-Açu: Relatório Geral. 132 p.

FEPAM (2001). Diagnóstico ambiental da bacia do rio Taquari Antas - RS: Diretrizes regionais para o licenciamento ambiental das hidrelétricas. Porto Alegre: FEPAM. (não publicado).

FEPAM (2003). Análise das fragilidades ambientais e da viabilidade de licenciamento de aproveitamentos hidrelétricos das bacias hidrográficas dos rios ljuí e Butuí - Piratinim - Icamaquã - Região da bacia do rio Uruguai - RS. In: Cadernos de Planejamento e Gestão Ambiental $n^{\circ}$ 5. Porto Alegre: FEPAM.

FERNANDES (2008). Modelo para aplicação de critérios ambientais para licenciamento de empreendimentos hidrelétricos: um estudo de caso na sub-bacia hidrográfica do rio Benedito - SC. Dissertação (Mestrado em Engenharia Ambiental). Programa de Pós-Graduação em Engenharia Ambiental, Universidade Regional de Blumenau. Blumenau, 178p.

HARO, A. J. et al. (1991). Thermal preferenda and behavior of Atlantic eels (genus Anguilla) in relation to their spawning migration. Env. Biol. Fisch. 31, pp.171-184. 
LEE, N.; WALSH, F. (1992). Strategic environmental assessment. In: Overview, Project Appraisal, v. 7, nº 32, pp. 126-136.

LOCATELLI, N. D. (2003). Uma contribuição à gestão de recursos hídricos na bacia do rio Itajaí: avaliação da qualidade das águas. Dissertação. (Mestrado em Engenharia Ambiental). Programa de Pós-Graduação em Engenharia Ambiental, Universidade Regional de Blumenau. Blumenau. $72 \mathrm{p}$.

MAZZONI, R.; LOBON-CERVIÁ, J. (2000). Longitudinal structure, densyte and production rates of a neotropical stream fish assemblage : the river Ubatiba in the Serra do Mar, Southeast Brazil. Ecography 23:588-602.

MISERENDINO, M. (2001). Macroinvertebrate assemblages in Andean Patagonian Rivers and streams: environmental relationships. Hydrobiologia 444: 147-158.

ORTIZ, A. I. (2003). Indicadores da qualidade da água em micro bacias agrícolas. Dissertação (Mestrado em Engenharia Ambiental). Programa de Pós-Graduação em Engenharia Ambiental, Universidade Regional de Blumenau. Blumenau. 144 p.

PARTIDÁRIO, M. R. (1999). Strategic environmental assessment: principles and potencial. In: Handbook on environmental impact assessment. Londres: Judith Petts Editora, pp. 60-73.

PINHEIRO, A.; BRAMORSKI, J. ; CRESPO, P. G. (2002). Quantificação da produção de sedimentos em suspensão na bacia do rio Itajaí. In: Revista de Estudos Ambientais, v.4, n.1, pp. 115-122, jan./abr.

PINHEIRO, A. (2004). Monitoramento e avaliação da qualidade das águas. In: Avaliação e contabilização de impactos ambientais. ROMEIRO, A. R. (org.). Campinas: Editora da UNICAMP; São Paulo: Imprensa Oficial do Estado de São Paulo.

PROSUL/RTK (2002-2003). Estudo de sustentabilidade ambiental: empreendimentos hidrelétricos no rio Caveiras - SC. 144 p.

RODRIGUES, R. R.; LEITÃO FILHO, H. de F. (2000). Matas ciliares: conservação e recuperação. São Paulo: EDUSP: FAPESP, 320p.

SABINO, J.; CASTRO, R. C. M. (1990). Alimentação, período de atividade e distribuição espacial dos peixes de um riacho da floresta atlântica (Sudeste do Brasil). In: Brasil Biol. 50 (1): 23-36.

SABINO, J.; ZUANON, J. (1998). A stream fish assemblage in Central Amazônia: distribution activity patterns and feeding behaviour. In: Ichthyol. Explor. Freshwaters 8 (3) : 201-210.

SHEAT, W. R. (1992). Lobbying for effective environmental assessment : long range planning. v. 25, pp.90-98.

SOMA - Soluções em Meio Ambiente (2002). Avaliação ambiental estratégica como instrumento de licenciamento para hidrelétricas: 0 caso da bacia do rio Chopim no Paraná. Curitiba: SOMA.

THÉRIVEL, R. et al. (1992). Strategic environmental assesment. London : Earthscan Publications Ltd.

TUCCI, C. E. M. (2006) Avaliação ambiental integrada de bacias hidrográficas. Brasília: MMA; PNUD. 362 p.

UIEDA, V. S. ; UIEDA, W. (2001) Species composition and spatial distribution of a stream fish assamblage in the east coast of Brasil: comparison of two Field study methodologies. In: Brazilian Journal of Biology 61 (3): 377-388.

VIANA, V. M. et al. (1992) Restauração e manejo de fragmentos florestais. In: Congresso Nacional sobre Essências Nativas, 2, São Paulo, 1992, Anais. São Paulo: Instituto Florestal de São Paulo, 1992, p.400-407.

WILSON, E. (1993). Strategic environmental assessment: evaluating the impacts of European policies, plans and programmes. In: European Environment. v. 3, part. 2, pp.2-6.

Odair Fernandes Geógrafo, Mestre em Engenharia Ambiental, sócio da CEPAN - Consultoria Energética e Projetos Ambientais Nascente do Vale, responsável pela área ambiental da Industrial e Agrícola Rio Verde e representante da Indústria do setor papeleiro no Comitê do Itajai. E-mail: odair@rioverde.ind.br

Noemia Bohn Professora da Universidade Regional de Blumenau - FURB, SC. Av. Antonio da Veiga, 140, Bairro Victor Konder, Blumenau, SC, 89012900. E-mail: noemia@furb.br. 